\title{
PENENTUAN JUMLAH TELLER YANG OPTIMAL DENGAN METODE ANTRIAN DI PT BANK HAGA
}

\author{
Bahtiar S. Abbas'; Raymond ${ }^{2}$
}

\begin{abstract}
This article presents the optimization of the number of tellers at the service counter at PT BANK Haga. Its done by comparing the some alternatives related to the number of tellers employed. Conclusion indicates that optimal condition is that 5 tellers at Abdul Muis Branch and 4 tellers at Daan Mogot Branch.
\end{abstract}

Keywords: teller, queue, bank

\section{ABSTRAK}

Artikel menyajikan laporan mengenai upaya optimalisasi jumlah teller untuk layanan di Bank Haga. Kajian dilakukan dengan membandingkan beberapa alternatif yang terkait dengan jumlah teller yang dipekerjakan. Hasil kajian menunjukkan bahwa jumlah teller yang optimal untuk kondisi PT Bank Haga Abdul Muis adalah 5 orang dan untuk PT Bank Haga cabang Daan Mogot 4 orang.

Kata kunci: teller, antri, bank

\footnotetext{
${ }^{1}$ Staf pengajar Fakultas Ekonomi, UBiNus, Jakarta

${ }^{2}$ Sarjana Teknik, Jurusan Teknik Industri, Fakultas Teknik, UBiNus, Jakarta
} 


\section{PENDAHULUAN}

Dengan semakin maju dan banyaknya usaha perbankan yang berkembang di Indonesia, diperlukan suatu kemampuan menunjukkan performansi yang baik guna memenangkan persaingan. Salah satu performansi yang perlu diperhatikan adalah tingkat pelayanan kepada konsumen. Untuk mencapai performansi yang baik, banyak bank memberikan kemudahan kepada konsumennya, misalnya dalam bentuk kecepatan mendapatkan pelayanan. Namun demikian, masih sering dijumpai begitu panjangnya antrian di bank karena banyaknya nasabah yang belum dapat dilayani. Hal itu tentunya menimbulkan kerugian baik bagi pemilik bank maupun konsumen. Lamanya pelayanan karena panjangnya antrian menyebabkan konsumen menjadi malas untuk melakukan transaksi di bank tersebut. Akibatnya, bank kehilangan konsumen. Oleh karena itu, dibutuhkan suatu pelayanan yang cepat antara lain menentukan jumlah operator yang tepat agar tercapai tingkat pelayanan yang optimal. Sebagai salah satu bank, PT Bank Haga juga mengalami kendala yang sama dalam memaksimalkan pelayanan mereka.

Tujuan penelitian ini adalah (1) untuk mengetahui kondisi tingkat pelayanan di PT Bank Haga Abdul Muis dan PT Bank Haga cabang Daan Mogot sehingga dapat diketahui efisiensi kerja yang lebih baik antara PT Bank Haga Abdul Muis atau PT Bank Haga cabang Daan Mogot; (2) untuk mengetahui total biaya sistem di PT Bank Haga Abdul Muis maupun di PT Bank Haga cabang Daan Mogot; (3) untuk mengetahui jumlah teller yang optimal untuk meminimasi total biaya sistem dan memaksimalkan tingkat pelayanan; (4) untuk mengetahui model antrian yang diterapkan di Bank Haga.

\section{Metode Penelitian}

\section{Pemilihan Model Antrian}

Untuk menentukan suatu model yang tepat dalam memecahkan masalah yang terjadi, penulis melakukan pengamatan secara langsung di PT Bank Haga Abdul Muis dan PT Bank Haga cabang Daan Mogot. Pengamatan yang dilakukan sebagai berikut.

1. Bagaimana pola kedatangan nasabah dan pola pelayanan pada sistem antrian di PT Bank Haga Abdul Muis dan PT Bank Haga cabang Daan Mogot.

2. Bagaimana pola disiplin pelayanan yang berlaku di PT Bank Haga Abdul Muis dan PT Bank Haga cabang Daan Mogot, misalnya apakah nasabah yang datang terlebih dahulu akan dilayani terlebih dahulu juga (First Come First Served).

3. Bagaimana jumlah saluran pelayanan yang dipakai, dalam hal ini adalah jumlah teller, apakah tunggal atau banyak.

\section{Pengumpulan Data}

Dalam proses pengumpulan data didapatkan sejumlah data berupa data waktu pelayanan dan data waktu antarkedatangan konsumen. Pengambilan data dilakukan selama \pm 3,5 jam, dimulai dari pukul 09.30 s.d. 13.00 WIB. Selain data primer, penulis juga mengumpulkan sejumlah data sekunder yang didapatkan dari wawancara dengan para operator yang bekerja di PT Bank Haga. Alat yang digunakan oleh penulis dalam melakukan pengumpulan data antara lain (1) Stopwatch digunakan untuk mengukur waktu pelayanan teller terhadap nasabah dan untuk mengukur waktu antarkedatangan nasabah dan (2) pena dan kertas digunakan untuk mencatat hasil pengukuran data. 


\section{Uji Kebaikan Suai (Test Goodness of Fit)}

Setelah data dikumpulkan maka langkah selanjutnya adalah melakukan pengolahan data. Pengolahan data yang dilakukan adalah melakukan uji kesesuaian bentuk distribusi Poisson dan uji distribusi eksponensial. Pengujian bentuk distribusi yang dilakukan adalah menguji apakah pola kedatangan konsumen mengikuti distribusi Poisson dan apakah waktu pelayanan mengikuti distribusi eksponensial. Caranya adalah menggunakan uji kebaikan suai. Rumus distribusi Poisson sebagai berikut.

$$
\mathrm{P}(\mathrm{x})=\frac{\lambda^{\mathrm{x}} \cdot \mathrm{e}^{-\lambda}}{\mathrm{x} !}
$$

$\mathrm{e} \quad=$ bilangan natural dan $\mathrm{e}=2,7828$

$\lambda \quad=$ rata-rata tingkat kedatangan

$\mathrm{x} \quad=$ banyaknya kedatangan

Rumus distribusi eksponensial sebagai berikut.

$$
f(x)=\mu e^{-\mu t}
$$

$\mathrm{t} \quad=$ waktu pelayanan

$\mathrm{f}(\mathrm{t}) \quad=$ probabilitas yang berhubungan dengan $\mathrm{t}$

$\mu \quad=$ rata-rata tingkat pelayanan sehingga $1 / \mu=$ rata-rata waktu pelayanan

Rumus Uji Kebaikan Suai sebagai berikut.

$$
\mathrm{x}^{2}=\sum_{i=1}^{\mathrm{c}} \frac{(\mathrm{fi}-\mathrm{ei})^{2}}{\mathrm{ei}}
$$

$\mathrm{fi}=$ frekuensi observasi

ei $=$ frekuensi teoritis

\section{Evaluasi Operating Characteristics}

Setelah mengetahui bentuk distribusi sistem, langkah selanjutnya adalah mencari operating characteristic-nya. Dari langkah tersebut, dapat ditentukan sebagai berikut.

1. Total biaya untuk sistem pelayanan yang berlaku sekarang di PT Bank Haga Abdul Muis dan PT Bank Haga cabang Daan Mogot.

2. Perbandingan sistem pelayanan yang berlaku di PT Bank Haga Abdul Muis dengan sistem pelayanan yang berlaku di PT Bank Haga cabang Daan Mogot.

3. Total biaya untuk sistem pelayanan optimal di PT Bank Haga Abdul Muis dan PT Bank Haga cabang Daan Mogot.

4. Jumlah sistem pelayanan optimal untuk PT Bank Haga Abdul Muis dan PT Bank Haga cabang Daan Mogot. 
Rumus operating characteristics untuk multiple server sebagai berikut.

$$
\begin{aligned}
& \mathrm{P}_{\mathrm{o}}=\frac{1}{\sum_{\mathrm{n}=0}^{\mathrm{S}-1} \frac{(\lambda / \mu)^{\mathrm{n}}}{\mathrm{n} !}+\frac{(\lambda / \mu)^{\mathrm{S}}}{\mathrm{s} !} \frac{1}{1-\lambda / \mathrm{s} \mu}} \\
& \mathrm{W}_{\mathrm{q}}=\frac{\mathrm{L}_{\mathrm{q}}}{\lambda} \\
& \mathrm{W}=\mathrm{W}_{\mathrm{q}}+1 / \mu \\
& \mathrm{L}_{\mathrm{q}}=\frac{\mathrm{P}_{0}(\lambda / \mu)^{\mathrm{n}} \cdot \lambda / \mathrm{c} \mu}{\mathrm{c} !(1-\lambda / \mathrm{c} \mu)^{2}} \\
& \mathrm{~L}=\mathrm{L}_{\mathrm{q}}+\lambda / \mu \\
& \mathrm{Po} \quad=\text { Probabilita tidak ada pengantri dalam sistem } \\
& \mathrm{L} \quad=\text { jumlah konsumen dalam sistem antrian yang diharapkan } \\
& \mathrm{L}_{\mathrm{q}} \quad=\text { panjang antrian yang diharapkan } \\
& \mathrm{W}=\text { waktu menunggu dalam sistem yang diharapkan termasuk waktu pelayanan } \\
& \mathrm{W}_{\mathrm{q}}=\text { waktu menunggu dalam antrian yang diharapkan } \\
& \text { Total Cost }(\mathrm{TC})=(\mathrm{c} x \text { Bp })+(\mathrm{L} \text { x Bm }) \\
& \mathrm{c} \quad=\text { jumlah operator } \\
& \mathrm{Bp} \\
& \mathrm{Bm}=\text { biaya pelayanan }
\end{aligned}
$$

\section{Evaluasi dan Analisis}

Berdasarkan hasil pengolahan data maka langkah selanjutnya melakukan evaluasi dan analisis terhadap sistem pelayanan yang berlaku sekarang dengan sistem pelayanan optimal di PT Bank Haga Abdul Muis dan PT Bank Haga cabang Daan Mogot. Tujuannya untuk mengetahui kelemahan yang ada pada sistem pelayanan di PT Bank Haga Abdul Muis dan PT Bank Haga cabang Daan Mogot berdasarkan total biaya sistem. Setelah mengetahui kelemahan yang ada, penulis berharap dengan sistem pelayanan optimal dapat lebih meningkatkan sistem pelayanan yang berlaku sekarang sehingga dapat memberikan keuntungan untuk PT Bank Haga Abdul Muis dan PT Bank Haga cabang Daan Mogot dan juga meningkatkan kepuasan para nasabah dalam pelayanan khususnya di bagian teller.

Pada akhirnya dapat ditarik suatu kesimpulan dari pengamatan yang telah dilakukan di PT Bank Haga Abdul Muis dan PT Bank Haga cabang Daan Mogot yang mungkin berguna bagi pihak PT Bank Haga serta saran dari penulis yang diharapkan dapat membantu segala kekurangan dari kinerja PT Bank Haga. 


\section{PEMBAHASAN}

\section{Hasil}

Berdasarkan hasil pengolahan data maka dapat ditentukan tingkat pelayanan dan tingkat kedatangan dari setiap kondisi yang dihitung. Hasil pengolahan data tersebut sebagai berikut.

1. Untuk PT Bank Haga Abdul Muis sebagai berikut.

$\lambda=0,59$ orang $/$ menit

$\mu=0,348$ orang/menit

2. Untuk PT Bank Haga cabang Daan Mogot sebagai berikut.

$\lambda=0,554$ orang $/$ menit

$\mu=0,358$ orang $/$ menit

Berdasarkan hasil pengolahan data tersebut maka dapat ditentukan jumlah teller yang optimal dengan tujuan minimumkan total biaya sistem. Sebelum melakukan pengolahan data, harus ditentukan model antrian yang digunakan. Berdasarkan pengamatan terhadap sistem pelayanan yang berlaku di Bank Haga Abdul Muis dan Bank Haga cabang Daan Mogot, dapat disimpulkan bahwa model antrian yang digunakan adalah $(\mathrm{M} / \mathrm{M} / \mathrm{c})$ : (FCFS / $/ \infty)$. Hal itu berdasarkan hal berikut.

1. Setiap nasabah yang datang terlebih dahulu ke fasilitas pelayanan akan langsung dilayani sehingga dapat disebut FCFS (First Come First Served).

2. Sumber input (nasabah) tidak terbatas.

3. Jumlah teller yang melayani lebih dari 1 orang.

4. Waktu antarkedatangan berdistribusi eksponensial yang berarti Tingkat kedatangan berdistribusi Poisson sedangkan tingkat pelayanan berdistribusi eksponensial. Untuk minimasi biaya total sistem, digunakan rumus berikut.

$$
\begin{aligned}
& \mathrm{TC}(\mathrm{c})=(\mathrm{c} . \mathrm{Bp})+(\mathrm{L} \cdot \mathrm{Bm}) \\
& \mathrm{Bp}=\text { Rp. } 120,00 / \text { menit } \\
& \mathrm{Bm}=\text { Rp. } 208,00 / \text { menit }, \text { bila } \mathrm{W}>3 \text { menit } \\
& \mathrm{Bm}=\text { Rp. } 0,00 / \text { menit }, \quad \text { bila } \mathrm{W} \leq 3 \text { menit }
\end{aligned}
$$

Berdasarkan hasil tersebut maka secara keseluruhan hasil perhitungan sebagai berikut.

1. Jumlah teller optimal PT Bank Haga Abdul Muis $=5$ orang.

2. Jumlah teller optimal PT Bank Haga cabang Daan Mogot $=4$ orang.

PT Bank Haga Abdul Muis saat ini menggunakan 8 orang teller dan PT Bank Haga cabang Daan Mogot saat ini menggunakan 3 orang teller. Berdasarkan hasil perhitungan dapat dilihat adanya penghematan biaya sebagai berikut.

1. Untuk PT Bank Haga Abdul Muis

Jika jumlah teller $=8$ orang, maka TC $=$ Rp. 958,33/menit

Jika jumlah teller $=5$ orang, maka $\mathrm{TC}=\mathrm{Rp} .598,96 /$ menit

Terjadi penghematan biaya sebesar berikut ini.

Rp. 958,33/menit - Rp. 598,96/menit = Rp. 359,37/menit $\sim$ Rp. 359,00/menit 
2. Untuk PT Bank Haga cabang Daan Mogot

Jika jumlah teller $=3$ orang maka $\mathrm{TC}=\mathrm{Rp} .737,60 /$ menit

Jika jumlah teller $=4$ orang maka $\mathrm{TC}=\mathrm{Rp} .479,17 /$ menit

Terjadi penghematan biaya sebesar berikut ini.

Rp. 737,60 / menit - Rp. 479,17 / menit =Rp 258,43 / menit $\sim$ Rp. 358,00/ menit

\section{Pembahasan}

Untuk saat ini, PT Bank Haga Abdul Muis menggunakan teller sebanyak 8 orang dan PT Bank Haga cabang Daan Mogot menggunakan teller sebanyak 3 orang. Berdasarkan hasil perhitungan, ternyata total biaya sistem di PT Bank Haga Abdul Muis lebih besar dibandingkan dengan PT Bank Haga cabang Daan Mogot. Hal itu karena jumlah operator yang tidak optimal sehingga terjadi penambahan biaya. Untuk jumlah teller di PT Bank Haga Abdul Muis dan PT Bank Haga cabang Daan Mogot, keduanya saat ini kurang efisien karena hal berikut.

1. Berdasarkan pengamatan, tingkat kedatangan di PT Bank Haga Abdul Muis cukup tinggi, namun jumlah teller yang bekerja di PT Bank Haga Abdul Muis melebihi jumlah yang optimal. Tingkat kedatangan di PT Bank Haga cabang Daan Mogot juga cukup tinggi, mendekati tingkat kedatangan di PT Bank Haga Abdul Muis $(\lambda=0,59$ orang/menit untuk PT Bank Haga Abdul Muis dan $\lambda=0,554$ orang/menit untuk PT Bank Haga cabang Daan Mogot) sehingga jumlah teller di PT Bank Haga cabang Daan Mogot ternyata kurang dari jumlah yang optimal. (jumlah teller PT Bank Haga cabang Daan Mogot $=3$ orang, jumlah teller PT Bank Haga cabang Abdul Muis $=8$ orang).

2. Tingkat pelayanan di kedua tempat yang masih rendah menyebabkan antrian yang panjang yang menyebabkan semakin tingginya biaya sistem.

Untuk kondisi PT Bank Haga cabang Abdul Muis yang menggunakan teller sebanyak 8 orang, kemungkinan tidak ada pengantri dalam sistem cukup tinggi. Akan tetapi, biaya sistem yang dibebankan juga semakin tinggi. Berdasarkan hasil perhitungan, jumlah teller yang optimal untuk PT Bank Haga Abdul Muis adalah sebanyak 5 orang dan total biaya sistem menggunakan 5 orang teller adalah yang paling minimum.

Untuk kondisi PT Bank Haga cabang Daan Mogot yang menggunakan teller sebanyak 3 orang, kemungkinan tidak ada pengantri dalam sistem cukup kecil sehingga menyebabkan antrian dalam sistem menjadi panjang. Antrian yang semakin panjang akan menyebabkan meningkatnya beban biaya menunggu. Selain itu, nasabah tidak akan melakukan transaksi lagi karena tingkat pelayanan yang buruk. Berdasarkan hasil perhitungan, jumlah teller yang optimal untuk PT Bank Haga cabang Daan Mogot adalah sebanyak 4 orang dan total biaya sistem menggunakan 4 orang teller adalah yang paling minimum. 


\section{PENUTUP}

\section{Simpulan}

1. Tingkat pelayanan PT Bank Haga Abdul Muis lebih rendah $(\mu=0,348$ orang/menit untuk $\lambda=0,59$ orang/menit) dibandingkan dengan tingkat pelayanan PT Bank Haga cabang Daan Mogot. ( $\mu=0,358$ orang/menit untuk $\lambda=0,554$ orang/menit).

2. Total biaya sistem PT Bank Haga Abdul Muis lebih tinggi dibandingkan dengan total biaya sistem PT Bank Haga cabang Abdul Muis.

3. Jumlah teller yang optimal untuk kondisi PT Bank Haga Abdul Muis $=5$ orang dan untuk PT Bank Haga cabang Daan Mogot $=4$ orang. Penambahan maupun pengurangan jumlah teller di PT Bank Haga saat ini menimbulkan penghematan yang cukup besar, yaitu untuk PT Bank Haga Abdul Muis = Rp. 359,00/menit dan untuk PT Bank Haga cabang Daan Mogot = Rp. $358,00 /$ menit

4. Model antrian yang digunakan oleh PT Bank Haga Abdul Muis dan PT Bank Haga cabang Daan Mogot adalah $(\mathrm{M} / \mathrm{M} / \mathrm{c}):(\mathrm{FCFS} / \infty / \infty)$.

\section{Saran}

1. Diharapkan pihak PT Bank Haga menggunakan tenaga kerja yang lebih terampil dengan tujuan lebih meningkatkan pelayanan. Hal itu dapat terwujud bila adanya kerja yang baik dari bagian Human Resources Development dalam merekrut tenaga kerja baru.

2. Tersedianya operator yang bertugas untuk mengamati kinerja sistem pelayanan PT Bank Haga secara periodik sehingga dapat diketahui apakah sistem pelayanan yang telah berjalan sudah efisien atau belum.

3. Perekrutan jumlah tenaga kerja yang tepat dengan tujuan meningkatkan efisiensi kerja.

4. Dilakukan perawatan terhadap beberapa peralatan secara berkala, dengan tujuan agar pekerjaan dapat dilakukan tanpa kesulitan karena adanya kerusakan peralatan. 


\section{DAFTAR PUSTAKA}

Dimyati, Tjutju Tarliah dan Ahmad Dimyati. 2002. Operation Research Model Pengambilan Keputusan. Bandung: Sinar Baru Algesindo.

Mulyono, Sri. 2002. Riset Operasi untuk Pengambilan Keputusan. Jakarta: Universitas Indonesia.

Supranto, Johannes. 1998. Riset Operasi untuk Pengambilan Keputusan. Jakarta: Universitas Indonesia.

Walpole, Ronald E. 1990. Pengantar Statistika. Edisi ke-3. Jakarta: PT Gramedia Pustaka Utama. 